\title{
Myocardial Lipid Profiling During Time Course of High Fat Diet and its Relationship to the Expression of Fatty Acid Transporters
}

\author{
Ewa Harasim Tomasz Stępek Karolina Konstantynowicz-Nowicka \\ Marcin Baranowski Jan Górski Adrian Chabowski \\ Department of Physiology, Medical University of Białystok, Białystok, Poland
}

\section{Key Words}

Cardiac muscle $•$ FAT/CD36 • Lipids • Mitochondria $\bullet$ Insulin resistance

\begin{abstract}
Background/Aims: It is well documented that increased fatty acids (FA) supply causes lipid accumulation and insulin resistance in skeletal muscles. Whether the same mechanism is present in the heart is still unclear. Therefore, the goal of our study was to determine the content of specific myocardial lipid fractions during feeding rats a high fat diet (HFD) for 5 weeks. Moreover, the relation between changes in myocardial lipid content, whole body insulin resistance and the expression of fatty acid transporters in each week of HFD was established. Methods: Gas liquid chromatography and high performance liquid chromatography were used to determine the content of lipid fractions in the left ventricle. Expression of selected proteins was estimated by Western blot technique. All measurements were made after each week of HFD. Results: As expected, lipid profile in myocardium was altered by HFD in different weeks of the study with the most intense changes in triacylglycerols, long chain fatty acid-CoA and ceramide. Furthermore, there was a significant elevation of plasmalemmal (the $4^{\text {th }}$ and the $5^{\text {th }}$ week) and mitochondrial expression (from the $3^{\text {rd }}$ to the $5^{\text {th }}$ week) of fatty acid translocase. Conclusion: High fat diet affects myocardial lipid profile in each week of its duration and causes alternations in FA metabolism in cardiomyocytes.
\end{abstract}

\section{Introduction}

Maintaining physiological contractile activity of the heart requires substantial energetic inputs. Therefore, it is important to supply appropriate amounts of substrates which are used in ATP production in cardiomyocytes, i.e. glucose, free fatty acids (FFA), lactate, ketone

Ewa Harasim 


\section{Cellular Physiology Cell Physiol Biochem 2015;37:1147-1158 \begin{tabular}{l|l} 
and Biochemistry & $\begin{array}{l}\text { DOI: 10.1159/000430238 } \\
\text { Published online: September 25, } 2015\end{array}$ \\
\hline
\end{tabular} \\ Harasim et al.: Myocardial Lipid Profile During High Fat Diet}

bodies and amino acids [1, 2]. Free fatty acids, apart from glucose, are the main source of energy in working heart, accounting for approximately $50-70 \%$ of the energy substrates used $[1,3]$. Healthy cardiac muscle is characterized by high rates of fatty acids metabolism and low myocellular lipids storage, thus supplying FFA to the cardiomyocytes from the plasma must be effective [4]. It is well known that blood-born FFA enter the cardiac myocytes both by passive diffusion (flip-flop process) and with participation of fatty acid transporting proteins. So far, in the heart three types of protein transporters have been identified. They are fatty acid translocase (FAT/CD36), plasma membrane fatty acid binding protein (FABPpm) and fatty acid transport proteins (FATP-1, FATP-4 and FATP-6) [5]. There is growing evidence that FAT/CD36 plays the pivotal role in regulating fatty acids uptake by cardiac myocytes. It was shown in the heart that FAT/CD36 relocates from intracellular depots to the sarcolemma, which results in substantial increase in FFA uptake (e.g. after insulin treatment or activation of AMP-dependent kinase) [6, 7]. Studies on FAT/CD36 knockout mice revealed that fatty acids transport into cardiomyocytes is mainly CD36-dependent due to marked reduction of FFA uptake by approximately $70 \%[8,9]$. Moreover, lack of FAT/ CD36 in animal models also affected lipids metabolism in cardiac and skeletal muscles by decreasing $\beta$-oxidation [10] and esterification of fatty acids [9]. Results of recent studies confirmed that permanent translocation of FAT/CD36 to the sarcolemma and high rates of fatty acids uptake result in augmented triacylglycerol (TAG) content in cardiac myocytes [11-13]. On the other hand, in skeletal muscles, a strong association between high fat diet and the accumulation of intramuscular lipids is quite well established. It is well known that insulin resistance in skeletal muscles is caused by elevated content of lipid in myocytes and increased plasmalemmal FAT/CD36 expression [14-16]. Whether it occurs in heart and how the content of specific lipid fractions might be affected in relation to the duration of high fat diet (HFD) is currently less known. Moreover, it is interesting whether there is an association between changes in myocardial lipid content and plasmalemmal expression of fatty acid transporters in each week of HFD feeding. Additionally, we wanted to check out whether there is a temporal association between administration of high fat diet, accumulation of myocardial lipids and whole body insulin resistance.

\section{Materials and Methods}

\section{Animals and study design}

Male Wistar rats (initial body mass $\sim 140 \mathrm{~g}$ ) were maintained at $20^{\circ} \mathrm{C}$ on a reversed light-dark cycle in approved animal holding facilities. Experiments were carried out after one week of acclimatization of the animals. Rats were randomly assigned to one of two dietary groups for 5 weeks; 1) control group, fed ad libitum on a standard chow (kcal distribution $=62 \%$ carbohydrate, $16 \%$ fat and 22\% protein; Agropol, Motycz, Poland) for rodents, or 2) high fat diet group fed ad libitum on a rodent diet rich in fatty acids (kcal distribution $=60 \%$ fat, $20 \%$ carbohydrate and 20\% protein; Research Diet INC, D12492). In our experiment two control groups were set at the beginning (the $1^{\text {st }}$ week) and at the end (the $5^{\text {th }}$ week) of the study (instead of 6 respectively to each single week of the diet to minimize the number of animals used in experiment in accordance with the requirements of local ethical committee on animal care). In these control groups the same measurements were made as in HFD groups. There were no significant changes between these two control groups, hence the results were referred as one control group (week 0). Body mass was monitored throughout the study. At the end of each experimental week (1, 2, 3, 4 and 5) rats (fasted overnight) were anaesthetized by intraperitoneal injection of pentobarbital ( $80 \mathrm{mg}$ per kilo of body weight). Samples of the left ventricle were excised, immediately freeze - clamped with aluminum tongs precooled in liquid nitrogen. Furthermore, left ventricles were weighted at the end of each week in all groups. There were no significant changes in heart weights (\% of body mass) in HFD groups compared to the control group (data not shown). Blood was collected in heparinized tubes, centrifuged and the plasma was separated. All samples (left ventricle and plasma) were stored at $-80^{\circ} \mathrm{C}$ until further analysis. Data from each experimental week are based on six independent determinations $(n=6)$. All experimental procedures and the number of animals were approved by the ethics committee on animal care at the Medical University of Bialystok.

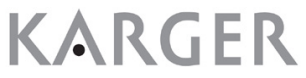




\section{Cellular Physiology Cell Physiol Biochem 2015;37:1147-1158 \begin{tabular}{ll|l} 
and Biochemistry & $\begin{array}{l}\text { DOI 10.1159/000430238 } \\
\text { Published online: September 25, } 2015\end{array}$ & $\begin{array}{l}\text { O 2015 S. Karger AG, Basel } \\
\text { www.karger.com/cpb }\end{array}$ \\
\cline { 2 - 3 }
\end{tabular} \\ Harasim et al.: Myocardial Lipid Profile During High Fat Diet}

\section{Plasma measurements}

Concentrations of plasma glucose, insulin and free fatty acids were determined with the use of AccuChek (Bayer, Basel, Switzerland) glucose-meter, Rat Insulin ELISA kit (Mercodia, Uppsala, Sweden) and gas-liquid chromatography (GLC), respectively. Concentrations of fasting glucose and insulin were used to calculate insulin resistance index $($ HOMA-IR = fasting glucose $(\mathrm{mmol} / \mathrm{l}) \times$ fasting insulin $(\mu \mathrm{U} / \mathrm{ml}) / 22.5)$.

\section{Subcellular fractionation of cardiac myocytes}

Subcellular fractionation of cardiac myocytes was performed to examine changes in the expression of FAT/CD36 and FABPpm at the level of plasma membranes (PM) and low density microsomes (LDM). Subcellular fractionation of the left ventricle was performed by using procedures previously described $[6,17,18]$. Briefly, after thawing, hearts were thoroughly minced and incubated for $30 \mathrm{~min}$ in a high-salt solution ( $2 \mathrm{~mol} / \mathrm{l} \mathrm{NaCl}, 20 \mathrm{mmol} / \mathrm{l} \mathrm{HEPES} \mathrm{pH} \mathrm{7.4,5} \mathrm{mmol} / \mathrm{l} \mathrm{NaN}{ }_{3}$ and protease inhibitors) at $4^{\circ} \mathrm{C}$. Thereafter, the suspension was centrifuged for $5 \mathrm{~min}$ at $1000 \mathrm{~g}$ and the pellet was homogenized in $6.0 \mathrm{ml}$ TES-buffer (20 mmol/l Tris pH 7.4, $1 \mathrm{mmol} / \mathrm{l}$ EDTA, $250 \mathrm{mmol} / \mathrm{l}$ sucrose and protease inhibitors) using a tightly fitting 10-ml Potter-Elvejhem glass homogenizer with 10 strokes. The resulting homogenate was centrifuged for $5 \mathrm{~min}$ at $1000 \mathrm{~g}$, after which the pellet was rehomogenized in $4.0 \mathrm{ml}$ TES-buffer with 10 strokes and then recombined with the $1000 \mathrm{~g}$ supernatant. The homogenate was centrifuged for $10 \mathrm{~min}$ at $100 \mathrm{~g}$. After centrifugation resulting pellet (P1) was resuspended in $300 \mu \mathrm{l}$ TES-buffer and saved. The supernatant was centrifuged for $10 \mathrm{~min}$ at 5,000 g. Next the pellet (P2) was resuspended in $300 \mu \mathrm{l} \mathrm{TES-buffer} \mathrm{and} \mathrm{saved.} \mathrm{The}$ supernatant was centrifuged for $20 \mathrm{~min}$ at 20,000 g. The pellet (P3) was resuspended in $300 \mu \mathrm{l}$ TES-buffer and saved. Next the supernatant was centrifuged for $30 \mathrm{~min}$ at 48,000 g. The pellet (P4) was resuspended in $150 \mu \mathrm{l}$ TES-buffer and saved. The supernatant was centrifuged for $65 \mathrm{~min}$ at 250,000 $\mathrm{g}$ and received pellet (P5) was resuspended in $150 \mu \mathrm{l}$ TES-buffer and saved. It has been established upon analysis of P1-P5 with ATPase sodium/potassium pump $\left(\mathrm{Na}^{+} / \mathrm{K}^{+}\right)$and glucose transporter 4 (Glut-4), that fractions P2 refers as PM-fraction and P5 as LDM-fraction $[18,19]$.

\section{Isolation of mitochondria}

Mitochondria were isolated from the left ventricle by using trypsin digestion method [20, 21]. In brief, the left ventricle was minced into small pieces and suspended in $10 \mathrm{ml}$ of isolation buffer $(0.3 \mathrm{M}$ sucrose, $10 \mathrm{mM}$ sodium HEPES, pH 7.2, $0.2 \mathrm{mM}$ EDTA). Next, to the isolation buffer with myocardial tissue trypsin was added and samples were incubated for $15 \mathrm{~min}$. After trypsin digestion samples were diluted with 10 $\mathrm{ml}$ of isolation buffer containing bovine serum albumin (BSA) and trypsin inhibitor. The suspension was mixed, and the supernatant was discarded. Thereafter, digested myocardial tissue was resuspended in 10 $\mathrm{ml}$ of isolation buffer with BSA and homogenized in glass homogenizer. The resulting homogenate was centrifuged for $10 \mathrm{~min}$ at $600 \mathrm{~g}$, after which the supernatant was centrifuged again (15 min, 8,000 g). The resulting pellet was resuspended in $10 \mathrm{ml}$ of isolation buffer with BSA and centrifuged (15min, $8000 \mathrm{~g}$ ). This step was repeated twice. The final pellet was resuspended in $500 \mu$ l of isolation buffer with BSA. Low temperature $\left(4^{\circ} \mathrm{C}\right)$ was maintained at each step of the procedure.

\section{Immunoblotting}

Routine Western blotting procedure was applied to detect proteins expression in myocardial plasma membranes, low density microsomes and mitochondria as it was described previously [22]. In all samples protein concentration was determined by using the bicinchonic acid method (BCA) with BSA as a standard. Briefly, after SDS poliacrylamide gel electrophoresis and transfer the membranes were incubated with primary antibodies FAT/CD36 (Abcam, UK), FABPpm (a gift from Dr. Calles-Escandon), cytochrome c oxidase (COX-4) and $\beta$-actin (Cell Signaling Technology, USA), $\beta$-hydroxyacyl-CoA dehydrogenase ( $\beta$-HAD) (Santa Cruz Biotechnology, USA). Signals obtained by immunoblotting were quantified densitometrically using a ChemiDoc visualization system (Bio Rad, Warsaw, Poland). Equal protein concentrations were loaded in each lane which was also confirmed by staining Ponceau S. Protein expression was standardized to $\beta$-actin expression and the control group was set as $100 \%$. Additionally, purity of isolated PM and LDM from the left ventricle was confirmed by measuring the expression of ATP-ase $\mathrm{Na}^{+} / \mathrm{K}^{+}$and Glut-4 (Santa Cruz Biotechnology, USA) according to Fuller et al. [18]. Furthermore, plasmalemmal and intramyocellular content of fatty acid transporters was standardized to ATP-ase $\mathrm{Na}^{+} / \mathrm{K}^{+}$(PM fraction) and Glut-4 (LDM 


\section{Cellular Physiology Cell Physiol Biochem 2015;37:1147-1158 \begin{tabular}{l|l} 
DOI: 10.1159/000430238 & (C) 2015 S. Karger AG, Basel
\end{tabular} and Biochemistry Published online: September 25, $2015 \quad$ www.karger.com/cpb \\ Harasim et al.: Myocardial Lipid Profile During High Fat Diet}

fraction) expression, respectively. Moreover, the purity of mitochondria was confirmed by measuring the expression of COX-4 (Cell Signaling Technology, USA).

\section{Intramyocardial lipid analyses}

The samples of the left ventricle were powdered and lipids were extracted in a chloroform-methanol solution according to the Folch method [23]. Lipid fractions of phospholipids (PL), FFA, diacylglycerols (DAG) and TAG were separated using thin-layer chromatography (TLC) [24]. Individual fatty acid methyl esters were identified and quantified according to the retention times of standards by GLC (Hewlett-Packard 5890 Series II gas chromatograph, HP-INNOWax capillary column). Total PL, FFA, DAG and TAG content was estimated as the sum of the particular fatty acid species of the assessed fractions and it was expressed in nanomoles per gram of tissue.

The content of ceramide (CER) was determined by using high performance liquid chromatography (HPLC) system as it was described previously [25]. Briefly, samples of the left ventricle were homogenized and lipids were extracted into chloroform. An aliquot of the lipid extract was transferred to a fresh tube with pre-added 40 pmol of N-palmitoyl-D-erythro-sphingosine (C17 base) (a kind of gift from Dr Z. Szulc, Medical University of South Carolina) as an internal standard. Thereafter, the samples were subjected to alkaline hydrolysis to deacylate ceramide. Free sphingosine released from ceramide was then converted to their o-phthalaldehyde derivatives and analyzed using a HPLC system equipped with a fluorescence detector and C18 reversed-phase column (Varian Inc. OmniSpher 5, $4.6 \times 150 \mathrm{~mm}$ ). The chloroform extract used for measurement of ceramide also contained small amounts of free sphingoid bases. Therefore, the content of ceramide was corrected for the level of free sphingosine determined in the same sample. Prior to the sphingolipid analysis, the protein content was measured in all samples with BSA as a standard and ceramide content was expressed in nanomoles per mg of the protein.

Content of long-chain fatty acyl-CoA (LCFA-CoA)

Total content of LCFA-CoA was estimated as it was described previously in details [25]. In brief, the amount of LCFA-CoA was measured indirectly after hydrolysis to free CoA according to the method of Ingebretsen et al. [26]. The samples of the left ventricle were homogenized in ice-cold 6\% perchloric acid and centrifuged (10 min, $1600 \mathrm{~g}$ ). Next, received pellet containing LCFA-CoA was washed twice with $0.6 \%$ perchloric acid and water, respectively. The pellet was resuspended by ultrasonication in water and 1.77 $\mathrm{M} \mathrm{KOH}$ and incubated $\left(60 \mathrm{~min}, 55^{\circ} \mathrm{C}\right)$. After incubation samples were cooled and $0.5 \mathrm{M}$ triethanolamine$\mathrm{HCl}$ in $6 \%$ perchloric acid was added. Thereafter, samples were centrifuged (10 min, $5200 \mathrm{~g}), 100 \mu \mathrm{l}$ of the supernatant was injected into the column (Varian Inc. OmniSpher 5, 4.6 $\times 150 \mathrm{~mm}$ ) and the content of released CoA was estimated with the HPLC system equipped with a UV detector using gradient elution. The content of LCFA-CoA in all samples was expressed in nanomoles per mass of wet tissue.

\section{Statistical analyses}

All data are expressed as mean values \pm SEM. Statistical difference between groups was tested with analyses of variance and appropriate post hoc tests, or with a Student t-test using Statistica version 10 (StatSoft, Krakow, Poland). Results were considered statistically significant at $\mathrm{P}<0.05$.

\section{Results}

Effect of HFD feeding on plasma glucose, insulin, HOMA-IR and free fatty acids

We observed significant increase in plasma glucose concentration by $+33.3 \%(\mathrm{P}<0.05)$ in the fourth week and by $+51.3 \%(\mathrm{P}<0.05)$ in the fifth week HFD compared to the control group (Fig. 1A). At the same time we noticed a substantial increase in insulin concentration by $+299.3 \%(P<0.05)$ in the fourth week and by $+269 \%(P<0.05)$ in the fifth week HFD in comparison with animals fed on standard chow (Fig. 1B). As expected, HOMA-IR, was increased at the end of feeding animals with HFD compared to the control group (the $4^{\text {th }}$ week: $+483.1 \%$; the $5^{\text {th }}$ week: $+581.3 \%, P<0.05$, Fig. 1 C). Interestingly, high fat diet had no effect on the plasma concentration of free fatty acids (Fig. 1D). 


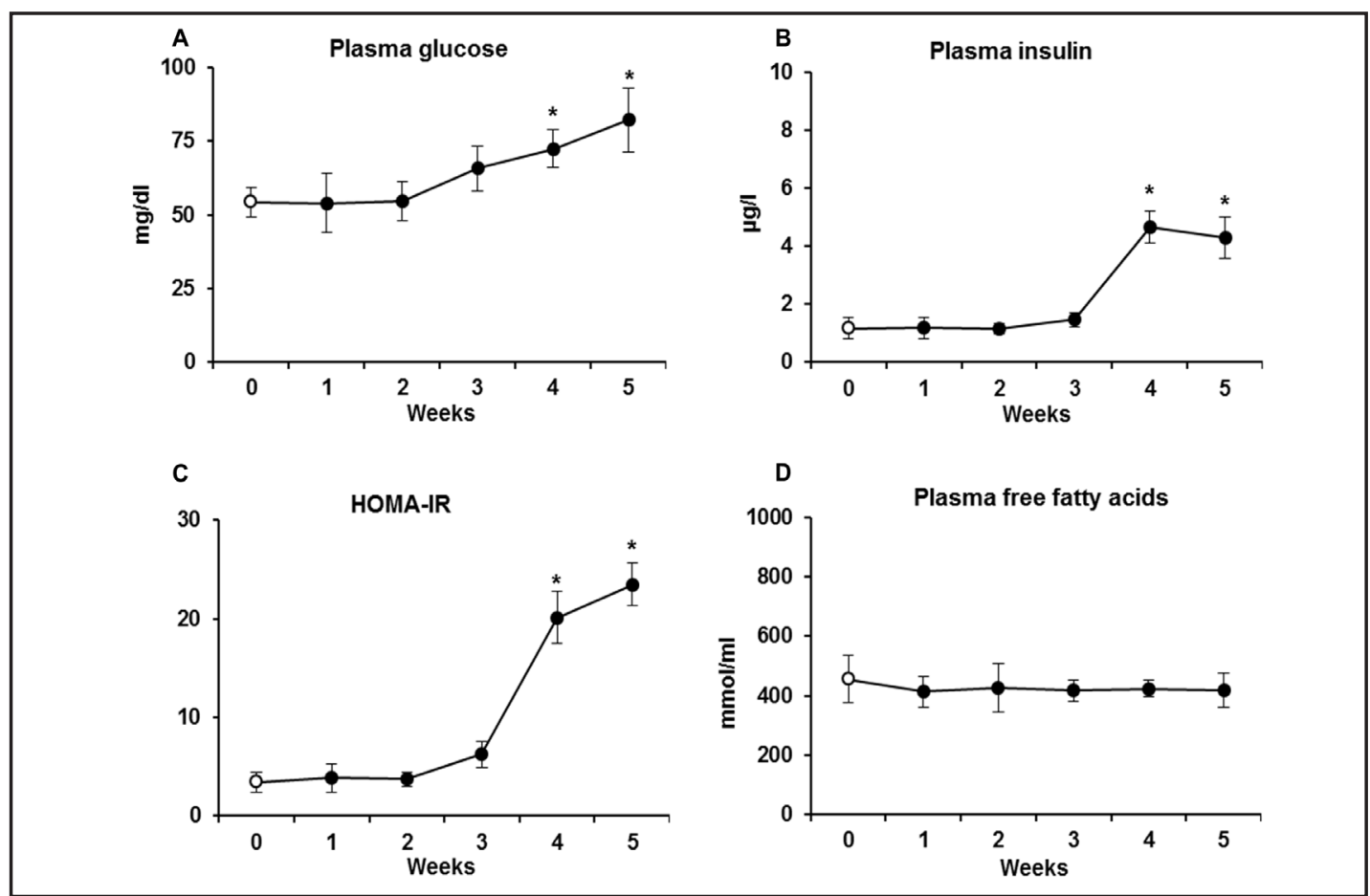

Fig. 1. Concentration of glucose (A), insulin (B) and free fatty acids (D) in plasma. HOMA-IR (C) was calculated by using plasma values of glucose and insulin. The data are expressed as the mean \pm SEM and are based on six independent determinations $(n=6)$. White dots are referred as Control group (week 0 ) and black dots as HFD groups from each experimental week $\left(1,2,3,4\right.$ and 5). ${ }^{*} \mathrm{P}<0.05$ significant difference: Control group vs. HFD groups.

Effect of HFD feeding on plasmalemmal and intramyocardial expression of FAT/CD36 and FABPpm in the left ventricle

Feeding on HFD caused a relocation of FAT/CD36 from intracellular compartments to the plasma membranes observed at the end of the fourth and the fifth week compared to the control group (PM, $+21.0 \%$ and $+23.5 \%, \mathrm{P}<0.05$, Fig. $2 \mathrm{~A}$, respectively). Moreover, there was a decreasing tendency of intramyocardial expression of FAT/CD36 in low density microsomes during time course of HFD, although it did not reach significant level ( $\mathrm{P}>0.05$, Fig. 2C). On the other hand, plasmalemmal and intramyocellular expression of FABPpm remained stable during each week of HFD regime ( $>0.05$, Fig. 2B and 2D).

Effect of HFD feeding on mitochondrial expression of FAT/CD36 and COX-4 in the left ventricle

Mitochondrial expression of FAT/CD36 increased at the end of the third week on HFD (the $3^{\text {rd }}$ week: $+22.2 \%$; the $4^{\text {th }}$ week: $+49.4 \%$; the $5^{\text {th }}$ week: $+22.0 \%, P<0.05$, Fig. $3 \mathrm{~A}$ ). Whereas, the content of $\beta$-HAD protein was significantly elevated as early as at the end of the first week and remained considerably increased in the following weeks of the experiment compared to the control group (the $1^{\text {st }}$ week: $+47.1 \%$; the $2^{\text {nd }}$ week: $+65.4 \%$; the $3^{\text {rd }}$ week: $+28.6 \%$; the $4^{\text {th }}$ week: $+46.7 \%$ and the $5^{\text {th }}$ week: $+32 \%$, P $<0.05$, Fig. $\left.3 \mathrm{~B}\right)$. However, we did not notice any changes in mitochondrial expression of COX-4 during HFD compared to the control group $(\mathrm{P}>0.05$, Fig. $3 \mathrm{C})$.

Effect of HFD feeding on myocardial lipid content (FFA, DAG, PL, TAG, CER and LCFA-CoA)

A trend towards increase in myocardial level of FFA was observed during HFD regime, but only in the fifth week the significance was reached (+109.4\%, P $<0.05$, Fig. 4A). We did not notice any substantial changes in the level of DAG fraction $(\mathrm{P}>0.05$, Fig. $4 \mathrm{~B})$, whereas 


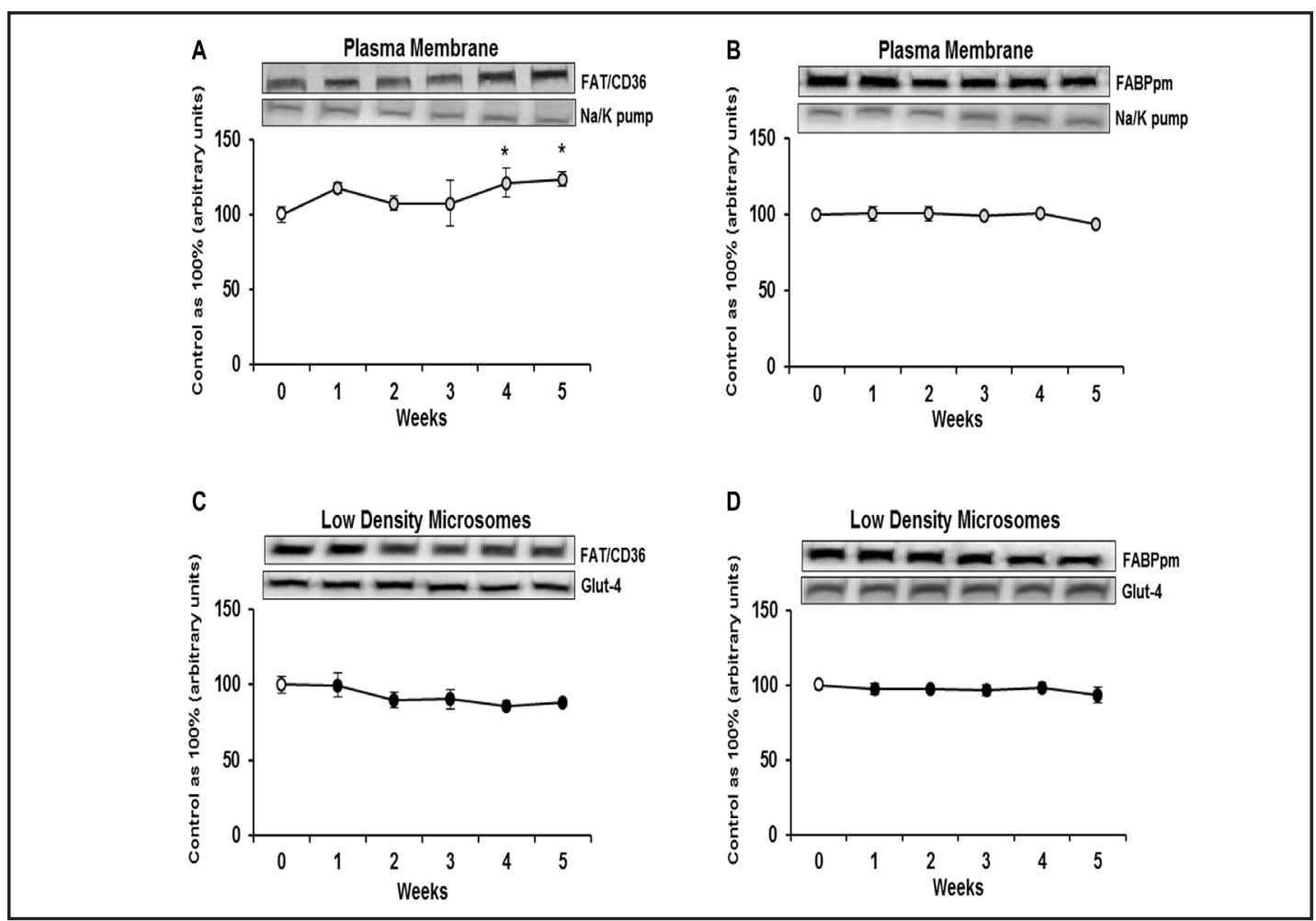

Fig. 2. Expression of FAT/CD36 (A and C) and FABPpm (B and D) in plasma membranes (PM) and low density microsomes (LDM) in myocardium after high fat feeding, respectively. The data are expressed as the mean \pm SEM and are based on six independent determinations $(n=6)$. Light grey dots are referred as PM and black dots as LDM in HFD groups (week 1, 2, 3, 4 and 5). White dots are referred as Control group. ${ }^{*} \mathrm{P}<0.05$ significant difference: Control group vs. HFD groups.
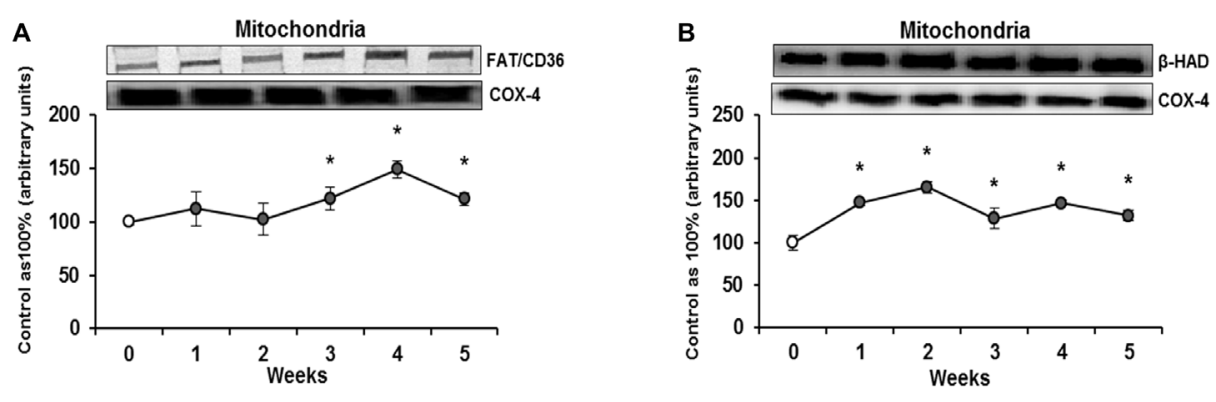

Fig. 3. Mitochondrial expression of FAT/CD36 (A), $\beta$-HAD (B) and COX-4 (C) in myocardium after high fat feeding. The data are expressed as the mean \pm SEM and are based on six independent determinations $(n=6)$. White dots are referred as Control group (week 0) and dark grey dots as HFD groups from each experimental week $(1,2,3,4$ and 5$) .{ }^{*} \mathrm{P}<0.05$ significant difference: Control group vs. HFD groups.

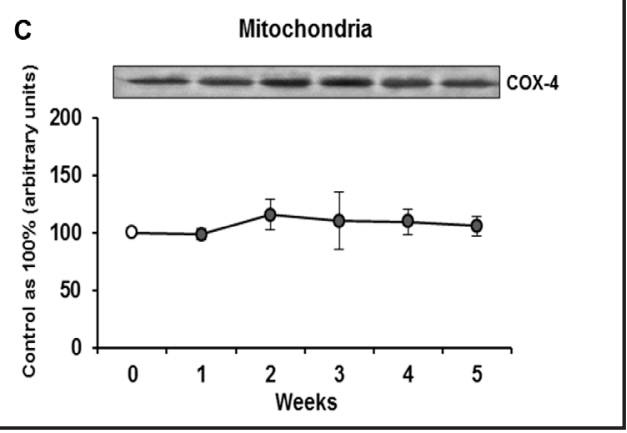

the content of PL in cardiac muscle was affected by HFD in each week with the considerable increase in the second and the third week in comparison with the standard chow $+25.9 \%$ 


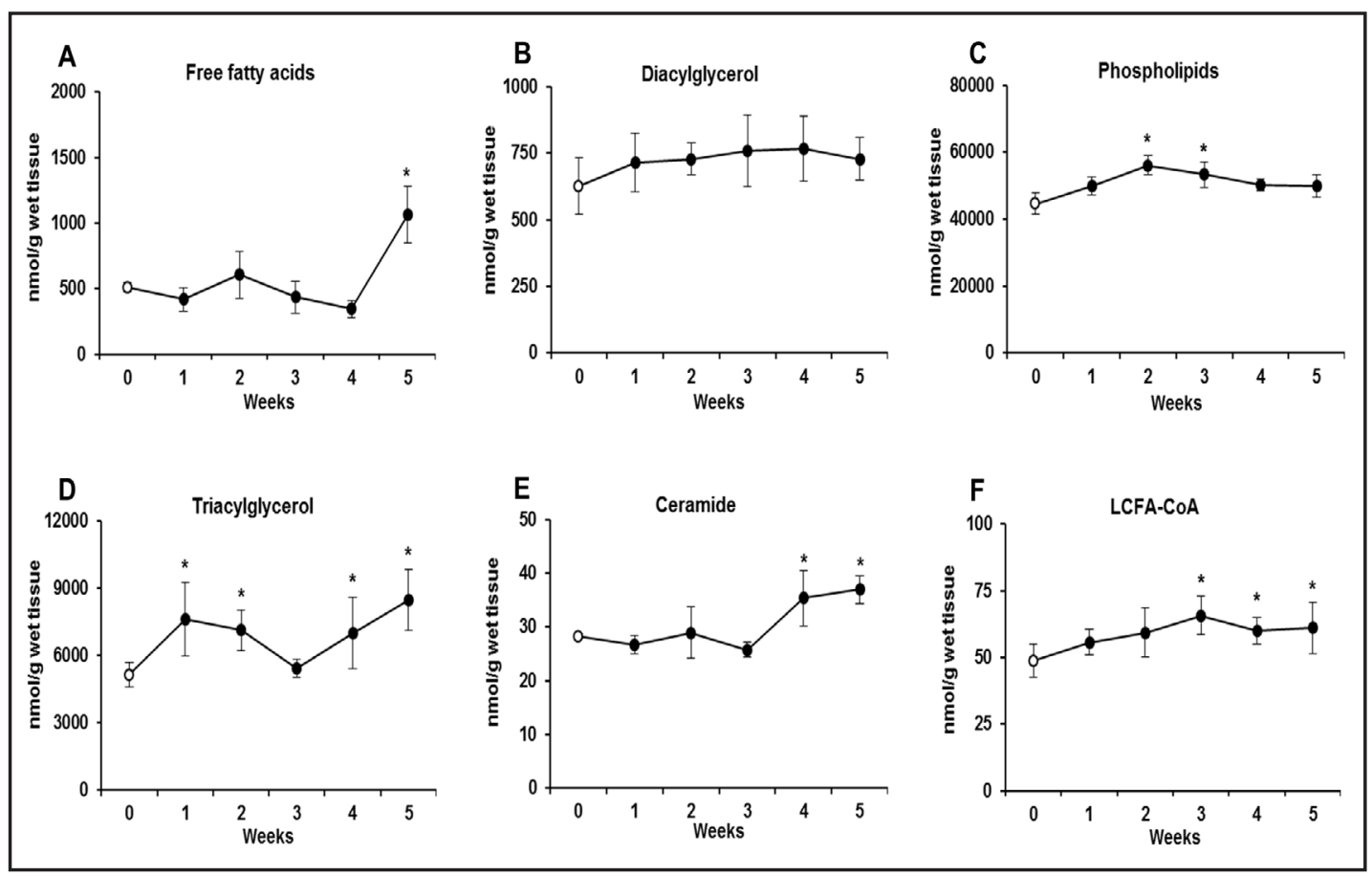

Fig. 4. Myocardial content of free fatty acids (A), diacylglycerol (B), phospholipids (C), triacylglycerol (D), ceramide $(\mathrm{E})$ and long chain fatty acids-CoA $(\mathrm{F})$. The data are expressed as the mean \pm SEM and are based on six independent determinations $(n=6)$. White dots are referred as Control group (week 0 ) and black dots as HFD groups from each experimental week (1, 2, 3, 4 and 5). ${ }^{*} \mathrm{P}<0.05$ significant difference: Control group vs. HFD groups.

and $+19.5 \%$, P $<0.05$, Fig. 4C, respectively). We recorded marked increase in the level of TAG in the left ventricle in all groups on HFD, with the exception for the third week compared to the control group (the $1^{\text {st }}$ week: $+48.1 \%$; the $2^{\text {nd }}$ week: $+38.8 \%$; the $4^{\text {th }}$ week: $+36.1 \%$ and the $5^{\text {th }}$ week: $+65.2 \%, P<0.05$, Fig. $4 \mathrm{D}$, respectively). Similarly to TAG fraction, the content of intramyocardial LCFA-CoA was substantially elevated in the third, fourth and fifth week on HFD $(+34.8 \%,+23.2 \%$ and $+25.4 \%, \mathrm{P}<0.05$, Fig. 4 F, respectively). Content of CER in the left ventricle increased significantly only at the end of our study (the $4^{\text {th }}$ week: $+25.2 \%$ and the $5^{\text {th }}$ week: $+31.0 \%$, P $<0.05$, Fig. $4 \mathrm{E}$ ).

\section{Discussion}

The purpose of our study was to assess how high availability of fatty acids affects myocardial lipid profile in rats fed on HFD for 5 weeks. Furthermore, all the measurements were made after each week of HFD, as we wanted to establish the exact time of imbalance in lipid metabolism in cardiac muscle. Moreover, we determined the presence of temporal association between the content of lipids in the left ventricle and the expression of fatty acid transporters at the plasma membranes (FAT/CD36, FABPpm) and mitochondria (FAT/CD36) during feeding on HFD. The data presented herein show that feeding rats a HFD reduces whole body insulin sensitivity at the end of diet regime (the $4^{\text {th }}$ and the $5^{\text {th }}$ week). Besides, excess lipid supply probably increases FFA utilization ( $\beta$-oxidation and esterification) and affects significantly lipid content in cardiac muscle in different weeks of the study, particularly by elevating intramyocardial TAG, LCFA-CoA, CER, and FFA fraction. Similarly, the expression of a key fatty acid transporter, FAT/CD36, also increased both in plasma membrane and mitochondria in the fourth and the fifth week of HFD. To sum up, our data indicate that 


\section{Cellular Physiology Cell Physiol Biochem 2015;37:1147-1158 \begin{tabular}{l|l} 
and Biochemistry Published online: September 25, 2015 & $\begin{array}{l}\text { DO 2015 S. Karger AG, Basel } \\
\text { www.karger.com/cpb }\end{array}$ \\
\hline
\end{tabular} \\ Harasim et al.: Myocardial Lipid Profile During High Fat Diet}

increased fatty acids supply causes concomitant elevation of fatty acid uptake by cardiac myocytes and alternations in metabolism of intramyocardial lipid fractions. We may assume that changes in myocardial lipid profile and utilization of fatty acids probably precedes the occurrence of hypertrophy of cardiac muscle, functional disturbances and heart failure (i.e. lipotoxicity).

Probably, significant elevation of FAT/CD36 expression at plasma membrane of cardiomyocytes at the end of the study increased fatty acid uptake in the left ventricle. Our data are in line with other animal models of obesity, insulin resistance and diabetes such as obese Zucker rats [12, 27, 28], db/db mice [13] and high fat diet rats [11]. In these studies it was shown that rise in fatty acid uptake resulted from abundance of FAT/CD36 at plasma membrane and permanent relocation of the transporter from intracellular depots to the sarcolemma of cardiac myocytes, which is consistent with our results (the $4^{\text {th }}$ and the $5^{\text {th }}$ week). Moreover, in these animal models it was demonstrated that there is a close association between increased plasmalemmal expression of FAT/CD36, fatty acid uptake and the intracellular accumulation of TAG in cardiomyocytes. In our present study we have also observed similar interdependence due to concomitant elevation of FAT/CD36 at sarcolemma and increased content of intramyocardial TAG, however it was seen only at the end of the HFD feeding (the $4^{\text {th }}$ and the $5^{\text {th }}$ week). Some authors indicate elevation of plasmalemmal FAT/CD36, as one of the main factors contributing to the accumulation of lipids in rat heart $[12,29]$ and precede the development of cardiac contractile dysfunction [11]. Yang et al. [30] have shown that FAT/CD36 deficiency in mice with cardiac specific overexpression of PPAR $\alpha$ prevents intramyocardial lipid accumulation and cardiac dysfunction. Furthermore, another studies demonstrated that elevated influx of FFA into the cardiomyocytes enhanced the rate of $\beta$-oxidation, but when the cytoplasmic content of FFA exceeded the demands of the cells, there was a shift towards esterification and intracellular accumulation of lipids instead of $\beta$-oxidation process $[31,32]$. Our observations indicate that after the third week of feeding on HFD, the balance between FAA uptake and oxidation is disrupted and the amount of intracellular LCFA-CoA exceeds the capacity of cardiac myocytes for its utilization. Furthermore, throughout the study there was a significant increase in expression of $\beta$-HAD protein. This indicates that probably each experimental week had elevated $\beta$-oxidation of fatty acids. Despite these changes, suggesting increased FA $\beta$-oxidation it appears that FA influx overcome oxidative capacity of cardiac myocytes and the accumulation of TAG and other lipid intermediates has occurred. Moreover, our results are in agreement with previous reports $[13,33,34]$ in which $\mathrm{db} / \mathrm{db}$ mice exhibited enhanced oxidation of lipids without any parallel changes in plasma concentrations of FFA or marker enzymes involved in $\beta$-oxidation process and mitochondrial electron transport chain in cardiomyocytes. Although we did not notice any changes in mitochondrial expression of COX-4 during HFD time course, the expression of mitochondrial FAT/CD36 and $\beta$-HAD was considerably augmented, which may suggest that oxidation of lipids in cardiomyocytes was enhanced. What is more, recent studies are also contradictory in terms of number of mitochondria, their morphology and respiratory function in the heart in animal models of insulin resistance, obesity and Type 2 diabetes [28, 35, 36]. At present, there are only a few contradictory reports obtained from rodent studies on the role of FAT/CD36 in cardiac [37] and skeletal muscles [38, 39] mitochondria. Nevertheless, there is some evidence confirming the presence of this transporter on the outer mitochondrial membrane in skeletal [39] and cardiac muscles [37] and functional contribution of FAT/CD36 to the regulation of mitochondrial fatty acid oxidation in response to various metabolic challenges $[39,40]$. The study by King et al. [37] also revealed that mitochondrial content of FAT/CD36 in the heart is 10-fold greater compared to skeletal muscles, which may confirm remarkable role of this transporter in the regulation of lipid oxidation in the heart. Summing up, we may assume that considerable and progressive accumulation of myocardial lipid from the end of the third week of feeding rats a HFD probably was caused by lipid overload despite enhanced $\beta$-oxidation.

Furthermore, it is well known that insulin by activating PI3 kinase pathway is able to induce translocation of FAT/CD36 (not FABPpm) to the sarcolemma thereby increasing fatty 


\section{Cellular Physiology Cell Physiol Biochem 2015;37:1147-1158 \begin{tabular}{l|l} 
and Biochemistry Published online: September 25, 2015 & $\begin{array}{l}\text { DO 2015 S. Karger AG, Basel } \\
\text { www.karger.com/cpb }\end{array}$ \\
\hline
\end{tabular} \\ Harasim et al.: Myocardial Lipid Profile During High Fat Diet}

acid influx into the cardiomyocytes $[19,41]$. It is very likely that in our study and similar models of insulin resistance [27] elevated expression of FAT/CD36 at the sarcolemma of cardiomyocytes (the $4^{\text {th }}$ and the $5^{\text {th }}$ week of HFD) resulted from increased translocation of FAT/CD36 to the plasma membrane due to significantly high concentrations of plasma insulin at the same time. Moreover, recent reports have indicated that increased basal Akt activity during HFD feeding [11] as well as PPARs activation [17] may be responsible for the permanent relocation of FAT/CD36 from intracellular compartments to the plasma membrane in the heart. Surprisingly, plasmalemmal expression of FABPpm in the left ventricle in contrast to FAT/CD36 did not change throughout five weeks of feeding rats a HFD, which is consistent with some other reports related to insulin resistance state (ZDF rats) [42]. Probably, lack of alternations in expression of FABPpm resulted from unchanged concentration of free fatty acids in plasma and insensitivity of this transporter to insulin stimulation [19].

Many studies performed on rodent and human skeletal muscle demonstrated that elevated levels of myocardial CER, DAG, FFA and LCFA-CoA apart from TAG fraction are toxic and detrimental [5]. Whether increased levels of lipid intermediates in myocardium impair glucose metabolism and cause cardiac dysfunction is currently unknown. In our study, we did notice that significant elevation of myocardial LCFA-CoA (from the $3^{\text {rd }}$ to the $5^{\text {th }}$ week) coincides with the increased plasmalemmal and mitochondrial expression of FAT/CD36. In physiological state most of cytoplasmic LCFA-CoA are preferentially directed towards $\beta$-oxidation. However, overload of LCFA-CoA may lead to enhanced esterification of fatty acids to TAG, DAG and CER fraction [43]. Therefore, increased content of LCFA-CoA in the left ventricle (from the $3^{\text {rd }}$ to the $5^{\text {th }}$ week) is another evidence for alternations in lipids utilization and accumulation of TAG and other lipid metabolites in response to HFD. Most data indicate that TAG is an inert fraction and has no influence on insulin signaling pathway and glucose metabolism in lipid overloaded heart and skeletal muscles. Additionally, the level of intramyocellular TAG is in equilibrium with other lipid intermediates (e.g. DAG and CER). Nevertheless, increased intracellular TAG probably may disrupt contractile activity of cardiac muscle [43]. Moreover, it is well known that in skeletal muscles DAG as well as CER is able to induce insulin resistance, thereby inhibiting glucose transport into the myocytes. Whether the same mechanism is present in the heart and is responsible for induction of myocardial insulin resistance is still unclear. However, it has been recently shown that elevated content of DAG is one of the potential causes of induction of myocardial insulin resistance in mice fed on HFD for 10 weeks as a result of activating protein kinase C (PKC), thereby inhibiting insulin signaling and reducing glucose oxidation in cardiomyocytes [44]. In our study DAG content was slightly elevated during each week on HFD. It suggests that the impact of this lipid fraction on glucose metabolism was minor. However, we did observe a marked increase of myocardial ceramide content (the $4^{\text {th }}$ and the $5^{\text {th }}$ week), which probably resulted from elevated intramyocellular content of LCFA-CoA in the left ventricle at that time. There are a few contradictory reports regarding increased myocardial content of ceramide and its potentially harmful effects on functioning of cardiomyocytes (i.e. activation of apoptosis). In vivo (ZDF rats) [45] and in vitro (isolated rat cardiomyocytes) [46] studies revealed that elevated level of myocardial ceramide was the main cause of induction of apoptosis in lipid overload state. However, the data were not confirmed in chronically fed rats (diet rich in saturated fatty acids) [47]. Hence, a mechanism by means of ceramide induces apoptosis in cardimyocytes in its early stage of development remains unclear and requires further elucidation.

In conclusion, this study has demonstrated for the first time that HFD in each week of its duration causes changes in the lipid profile in cardiac muscle. Dietary fatty acids significantly affected myocardial lipid metabolism (from the $3^{\text {rd }}$ to the $5^{\text {th }}$ week) mostly by elevating the content of TAG, LCFA-CoA, CER and FFA fraction. It is likely that at the end of the third week of HFD the amount of intramyocellular LCFA-CoA exceeded cardiac myoctes $\beta$-oxidation capacity and progressive myocardial lipid accumulation began. Probably, these alternations in lipid utilization may disrupt glucose metabolism and eventually may lead to 


\begin{tabular}{|c|c|c|}
\hline Cellular Physiology & Cell Physiol Biochem 2015;37:1147-1158 & \\
\hline and Biochemistr & $\begin{array}{l}\text { Dol: 10.1159/000430238 } \\
\text { Published online: September 25, } 2015\end{array}$ & $\begin{array}{l}\text { O } 2015 \mathrm{~S} \text {. Karger AG, Basel } \\
\text { www.karger.com/cpb }\end{array}$ \\
\hline
\end{tabular}

lypotoxicity and cardiomyopathy. Whether changes in cardiac lipid profile are detrimental for the functioning of the heart requires further investigation.

\section{Acknowledgements}

This work was supported by the Medical University of Bialystok (grant number 11418920L, 124-18526L and 144-18510L) and National Science Centre in Poland (grant number N N401 005236). The authors have no conflicts of interest to declare.

\section{Disclosure Statement}

The authors have no conflicts of interest to declare.

\section{References}

1 Lopaschuk GD, Belke DD, Gamble J, Itoi T, Schönekess BO: Regulation of fatty acid oxidation in the mammalian heart in health and disease. Biochim Biophys Acta 1994;1213:263-276.

2 Saddik M, Lopaschuk GD: Myocardial triglyceride turnover and contribution to energy substrate utilization in isolated working rat hearts. J Biol Chem 1991;266:8162-8170.

3 Neely JR, Morgan HE: Relationship between carbohydrate and lipid metabolism and the energy balance of heart muscle. Annu Rev Physiol 1974;36:413-459.

4 Stanley WC, Recchia FA, Lopaschuk GD: Myocardial substrate metabolism in the normal and failing heart. Physiol Rev 2005;85:1093-1129.

5 Glatz JF, Luiken JJ, Bonen A: Membrane fatty acid transporters as regulators of lipid metabolism: Implications for metabolic disease. Physiol Rev 2010;90:367-417.

6 Luiken JJ, Koonen DP, Willems J, Zorzano A, Becker C, Fischer Y, Tandon NN, Van Der Vusse GJ, Bonen A, Glatz JF: Insulin stimulates long-chain fatty acid utilization by rat cardiac myocytes through cellular redistribution of fat/cd36. Diabetes 2002;51:3113-3119.

7 Luiken JJ, Coort SL, Willems J, Coumans WA, Bonen A, van der Vusse GJ, Glatz JF: Contraction-induced fatty acid translocase/cd36 translocation in rat cardiac myocytes is mediated through amp-activated protein kinase signaling. Diabetes 2003;52:1627-1634.

8 Habets DD, Coumans WA, Voshol PJ, den Boer MA, Febbraio M, Bonen A, Glatz JF, Luiken JJ: Ampk-mediated increase in myocardial long-chain fatty acid uptake critically depends on sarcolemmal cd36. Biochem Biophys Res Commun 2007;355:204-210.

9 Coburn CT, Knapp FF, Febbraio M, Beets AL, Silverstein RL, Abumrad NA: Defective uptake and utilization of long chain fatty acids in muscle and adipose tissues of cd36 knockout mice. J Biol Chem 2000;275:3252332529.

10 Holloway GP, Jain SS, Bezaire V, Han XX, Glatz JF, Luiken JJ, Harper ME, Bonen A: Fat/cd36-null mice reveal that mitochondrial fat/cd36 is required to upregulate mitochondrial fatty acid oxidation in contracting muscle. Am J Physiol Regul Integr Comp Physiol 2009;297:R960-967.

11 Ouwens DM, Diamant M, Fodor M, Habets DD, Pelsers MM, El Hasnaoui M, Dang ZC, van den Brom CE, Vlasblom R, Rietdijk A, Boer C, Coort SL, Glatz JF, Luiken JJ: Cardiac contractile dysfunction in insulinresistant rats fed a high-fat diet is associated with elevated cd36-mediated fatty acid uptake and esterification. Diabetologia 2007;50:1938-1948.

12 Coort SL, Hasselbaink DM, Koonen DP, Willems J, Coumans WA, Chabowski A, van der Vusse GJ, Bonen A, Glatz JF, Luiken JJ: Enhanced sarcolemmal fat/cd36 content and triacylglycerol storage in cardiac myocytes from obese zucker rats. Diabetes 2004;53:1655-1663.

13 Carley AN, Atkinson LL, Bonen A, Harper ME, Kunnathu S, Lopaschuk GD, Severson DL: Mechanisms responsible for enhanced fatty acid utilization by perfused hearts from type 2 diabetic $\mathrm{db} / \mathrm{db}$ mice. Arch Physiol Biochem 2007;113:65-75. 


\section{Cellular Physiology Cell Physiol Biochem 2015;37:1147-1158 \begin{tabular}{l|l} 
DOI: 10.1159/000430238 & (C) 2015 S. Karger AG, Basel
\end{tabular} www.karger.com/cpb \\ Harasim et al.: Myocardial Lipid Profile During High Fat Diet}

14 Holloway GP, Benton CR, Mullen KL, Yoshida Y, Snook LA, Han XX, Glatz JF, Luiken JJ, Lally J, Dyck DJ, Bonen A: In obese rat muscle transport of palmitate is increased and is channeled to triacylglycerol storage despite an increase in mitochondrial palmitate oxidation. Am J Physiol Endocrinol Metab 2009;296:E738747.

15 Luiken JJ, Arumugam Y, Dyck DJ, Bell RC, Pelsers MM, Turcotte LP, Tandon NN, Glatz JF, Bonen A: Increased rates of fatty acid uptake and plasmalemmal fatty acid transporters in obese zucker rats. J Biol Chem 2001;276:40567-40573.

16 Hegarty BD, Cooney GJ, Kraegen EW, Furler SM: Increased efficiency of fatty acid uptake contributes to lipid accumulation in skeletal muscle of high fat-fed insulin-resistant rats. Diabetes 2002;51:1477-1484.

17 Kalinowska A, Górski J, Harasim E, Harasiuk D, Bonen A, Chabowski A: Differential effects of chronic, in vivo, ppar's stimulation on the myocardial subcellular redistribution of fat/cd36 and fabppm. FEBS Lett 2009;583:2527-2534.

18 Fuller W, Eaton P, Medina RA, Bell J, Shattock MJ: Differential centrifugation separates cardiac sarcolemmal and endosomal membranes from langendorff-perfused rat hearts. Anal Biochem 2001;293:216-223.

19 Chabowski A, Coort SL, Calles-Escandon J, Tandon NN, Glatz JF, Luiken JJ, Bonen A: The subcellular compartmentation of fatty acid transporters is regulated differently by insulin and by aicar. FEBS Lett 2005;579:2428-2432.

20 Saks VA, Kuznetsov AV, Kupriyanov VV, Miceli MV, Jacobus WE: Creatine kinase of rat heart mitochondria. The demonstration of functional coupling to oxidative phosphorylation in an inner membrane-matrix preparation. J Biol Chem 1985;260:7757-7764.

21 Boehm EA, Jones BE, Radda GK, Veech RL, Clarke K: Increased uncoupling proteins and decreased efficiency in palmitate-perfused hyperthyroid rat heart. Am J Physiol Heart Circ Physiol 2001;280:H977983.

22 Chabowski A, Żendzian-Piotrowska M, Konstantynowicz K, Pankiewicz W, Mikłosz A, Łukaszuk B, Górski $\mathrm{J}$ : Fatty acid transporters involved in the palmitate and oleate induced insulin resistance in primary rat hepatocytes. Acta Physiol (Oxf) 2013;207:346-357.

23 FOLCH J, LEES M, SLOANE STANLEY GH: A simple method for the isolation and purification of total lipides from animal tissues. J Biol Chem 1957;226:497-509.

24 van der Vusse GJ, Roemen TH, Reneman RS: Assessment of fatty acids in dog left ventricular myocardium. Biochim Biophys Acta 1980;617:347-349.

25 Baranowski M, Zabielski P, Blachnio A, Gorski J: Effect of exercise duration on ceramide metabolism in the rat heart. Acta Physiol (Oxf) 2008;192:519-529.

26 Ingebretsen OC, Normann PT, Flatmark T: Determination of coash by high-performance liquid chromatography and its application in the assay of long-chain acyl-coa derivatives. Anal Biochem 1979;96:181-188.

27 Coort SL, Luiken JJ, van der Vusse GJ, Bonen A, Glatz JF: Increased fat (fatty acid translocase)/cd36mediated long-chain fatty acid uptake in cardiac myocytes from obese zucker rats. Biochem Soc Trans 2004;32:83-85.

28 Holloway GP, Snook LA, Harris RJ, Glatz JF, Luiken JJ, Bonen A: In obese zucker rats, lipids accumulate in the heart despite normal mitochondrial content, morphology and long-chain fatty acid oxidation. J Physiol 2011;589:169-180.

29 Luiken JJ, Coort SL, Koonen DP, van der Horst DJ, Bonen A, Zorzano A, Glatz JF: Regulation of cardiac longchain fatty acid and glucose uptake by translocation of substrate transporters. Pflugers Arch 2004;448:115.

30 Yang J, Sambandam N, Han X, Gross RW, Courtois M, Kovacs A, Febbraio M, Finck BN, Kelly DP: Cd36 deficiency rescues lipotoxic cardiomyopathy. Circ Res 2007;100:1208-1217.

31 Coort SL, Bonen A, van der Vusse GJ, Glatz JF, Luiken JJ: Cardiac substrate uptake and metabolism in obesity and type-2 diabetes: Role of sarcolemmal substrate transporters. Mol Cell Biochem 2007;299:5-18.

32 Sharma S, Adrogue JV, Golfman L, Uray I, Lemm J, Youker K, Noon GP, Frazier OH, Taegtmeyer H: Intramyocardial lipid accumulation in the failing human heart resembles the lipotoxic rat heart. FASEB J 2004;18:1692-1700.

33 Carley AN, Semeniuk LM, Shimoni Y, Aasum E, Larsen TS, Berger JP, Severson DL: Treatment of type 2 diabetic $\mathrm{db} / \mathrm{db}$ mice with a novel ppargamma agonist improves cardiac metabolism but not contractile function. Am J Physiol Endocrinol Metab 2004;286:E449-455. 


\section{Cellular Physiology Cell Physiol Biochem 2015;37:1147-1158

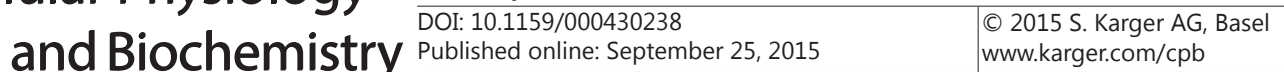 \\ Harasim et al.: Myocardial Lipid Profile During High Fat Diet}

34 Carley AN, Severson DL: Fatty acid metabolism is enhanced in type 2 diabetic hearts. Biochim Biophys Acta 2005;1734:112-126.

35 Littlejohns B, Lin H, Angelini GD, Halestrap AP, Suleiman MS: Switching back to normal diet following highfat diet feeding reduces cardiac vulnerability to ischaemia and reperfusion injury. Cell Physiol Biochem 2014;34:1090-1100.

36 Duncan JG, Fong JL, Medeiros DM, Finck BN, Kelly DP: Insulin-resistant heart exhibits a mitochondrial biogenic response driven by the peroxisome proliferator-activated receptor-alpha/pgc-1alpha gene regulatory pathway. Circulation 2007;115:909-917.

37 King KL, Stanley WC, Rosca M, Kerner J, Hoppel CL, Febbraio M: Fatty acid oxidation in cardiac and skeletal muscle mitochondria is unaffected by deletion of cd36. Arch Biochem Biophys 2007;467:234-238.

38 Campbell SE, Tandon NN, Woldegiorgis G, Luiken JJ, Glatz JF, Bonen A: A novel function for fatty acid translocase (fat)/cd36: Involvement in long chain fatty acid transfer into the mitochondria. J Biol Chem 2004;279:36235-36241.

39 Smith BK, Jain SS, Rimbaud S, Dam A, Quadrilatero J, Ventura-Clapier R, Bonen A, Holloway GP: Fat/cd36 is located on the outer mitochondrial membrane, upstream of long-chain acyl-coa synthetase, and regulates palmitate oxidation. Biochem J 2011;437:125-134.

40 Holloway GP: Mitochondrial function and dysfunction in exercise and insulin resistance. Appl Physiol Nutr Metab 2009;34:440-446.

41 Chabowski A, Górski J, Glatz JF, P Luiken JJ, Bonen A: Protein-mediated fatty acid uptake in the heart. Curr Cardiol Rev 2008;4:12-21.

42 Bonen A, Holloway GP, Tandon NN, Han XX, McFarlan J, Glatz JF, Luiken JJ: Cardiac and skeletal muscle fatty acid transport and transporters and triacylglycerol and fatty acid oxidation in lean and zucker diabetic fatty rats. Am J Physiol Regul Integr Comp Physiol 2009;297:R1202-1212.

43 Luiken JJ: Sarcolemmal fatty acid uptake vs. Mitochondrial beta-oxidation as target to regress cardiac insulin resistance. Appl Physiol Nutr Metab 2009;34:473-480.

44 Zhang L, Ussher JR, Oka T, Cadete VJ, Wagg C, Lopaschuk GD: Cardiac diacylglycerol accumulation in high fat-fed mice is associated with impaired insulin-stimulated glucose oxidation. Cardiovasc Res 2011;89:148156.

45 Zhou YT, Grayburn P, Karim A, Shimabukuro M, Higa M, Baetens D, Orci L, Unger RH: Lipotoxic heart disease in obese rats: Implications for human obesity. Proc Natl Acad Sci U S A 2000;97:1784-1789.

46 Dyntar D, Eppenberger-Eberhardt M, Maedler K, Pruschy M, Eppenberger HM, Spinas GA, Donath MY: Glucose and palmitic acid induce degeneration of myofibrils and modulate apoptosis in rat adult cardiomyocytes. Diabetes 2001;50:2105-2113.

47 Torre-Villalvazo I, Gonzalez F, Aguilar-Salinas CA, Tovar AR, Torres N: Dietary soy protein reduces cardiac lipid accumulation and the ceramide concentration in high-fat diet-fed rats and ob/ob mice. J Nutr 2009;139:2237-2243. 